\title{
Partial Synthesis of Crassicauline A from Yunaconitine
}

\author{
Rong-Ping Zhang ${ }^{1,2} \cdot$ Yan-Jun Lin ${ }^{2} \cdot$ Hao-Fei Yu ${ }^{2} \cdot$ Si-Ying Chen ${ }^{3} \cdot$ Jun Zhou ${ }^{3}$
}

Received: 10 January 2020 / Accepted: 19 March 2020 / Published online: 15 April 2020

(c) The Author(s) 2020

\begin{abstract}
Both Aconitum hemsleyanum and Aconitum geniculatun have abundant contents of yunaconitine (1). Yunaconitine (1) has similar skeleton to crassicauline A (3); the only difference between them is that $\mathbf{1}$ contains a $\alpha$-hydroxyl group at C-3. Our team attempts to convert $\mathbf{1}$ into $\mathbf{3}$ because $\mathbf{3}$ owns pharmacological activity. There are two steps to achieve the transformation above: firstly, use dehydration reaction to transform yunaconitine (1) into dehydroyunaconitine (2); secondly, use hydrogen reduction to acquire crassicauline A (3). Compared with other methods, this one below is more suitable for production application and more concise; moreover, the cost is lower with higher yield.
\end{abstract}

\section{Graphic Abstract}

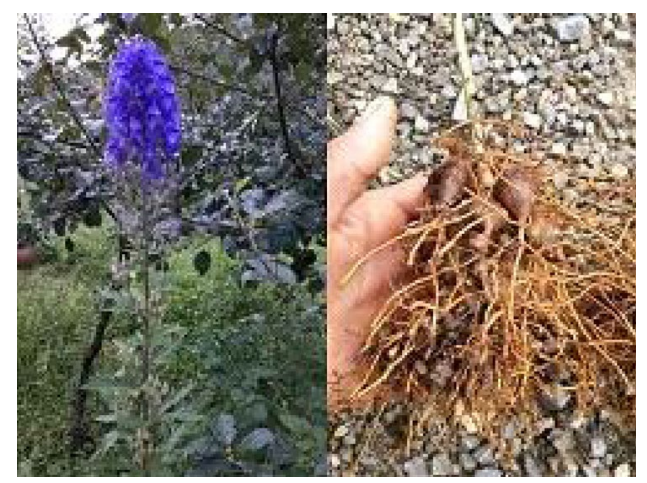

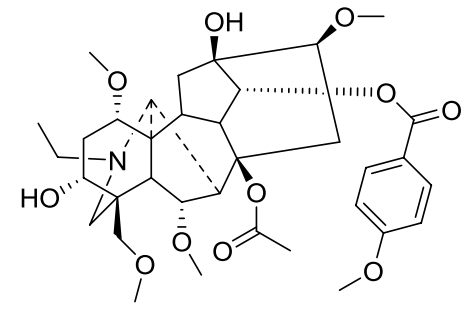

1

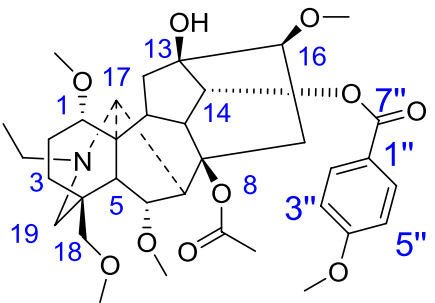

3

Aconitum stylosum Stapf

Keywords Diterpenoid alkaloids · Yunaconitine - Crassicauline A

Rong-Ping Zhang and Yan-Jun Lin have contributed equally to this work.

Dedicated to Professor Han-Dong Sun on the accession of his 80th birthday.

Jun Zhou

jzhou@mail.kib.ac.cn

Yunnan University of Chinese Medicine, Kunming, China

2 Kunming Medical University, Kunming, China

3 Kunming Institute of Botany, Chinese Academy of Sciences, Kunming, China

\section{Introduction}

Diterpenoid alkaloids are the main pharmacological constituents of Aconitum. Diterpenoid alkaloids have antiinflammatory, analgesic, sedative, antipyretic, and antineoplastic effection; the weight of them is accounting for about 7\%-10\% of Aconitum. Yunaconitine (1), as a C-19 diester diterpene alkaloid, distributes in almost the whole Yunnan Province; Aconitum hemsleyanum and A. geniculatum contains yunaconitine (1) [1-3] abundantly. However, 1 has very strong toxicity ( $\mathrm{LD}_{50}$ for mice is $585 \mu \mathrm{g} / \mathrm{kg}$ (i.p.), for rats is $50 \mu \mathrm{g} / \mathrm{kg}$ (i.v.), and for dogs is $30 \mu \mathrm{g} / \mathrm{kg}$ (i.v.) [4].). Additionally, although crassicauline A (3) has high treatment index, low toxicity, strong analgesic activity and no pain tolerance, 
it is lack of contents in Aconitum [5-9]. Moreover 3 [10] exists in a tiny minority of Acontium species that produced in Li Jiang, Yunnan, China. Hence, there is a high cost in the application of $\mathbf{3}$. At present, $\mathbf{3}$ has been widely used in clinical treatment for more than 30 years in China [4] including the treatment of rheumatoid arthritis, osteoarthritis, neuropathic and chronic pain. The main available dosage forms of crassicauline A (3) on the market include tablets, capsules, injections. Some studies have shown the subtle difference between 1 and 3: Yunaconitine (1) contains a $\alpha$-hydroxyl group at C-3; we believe that partial synthesis of $\mathbf{3}$ from $\mathbf{1}$ deserves to be mentioned.

A patent published by Zhang et al. [3] has reported four partial synthesis methods to afford crassicauline A (3) but the methods are complicated and difficult to purify the products with low yield. Therefore, we try to obtain semi synthetic $\mathbf{3}$ on the basis of increasing yield and getting a concise route.

\section{Results, Discussion and Conclusion}

At first, yunaconitine (1) was treated with thionyl chloride to acquire a dehydration product. Then the product was treated with silica gel column chromatography. After that, dehydroyunaconitine (2) (Fig. 1) was obtained. The ${ }^{1} \mathrm{H}$ NMR spectra $\left(\delta_{\mathrm{H}} 6.01,5.77\right)$ and ${ }^{13} \mathrm{C}$ NMR spectra $\left(\delta_{\mathrm{C}} 137.6,125.3\right)$ of 2 illustrated the presence of a double bond at C-2. Besides, in HRESIMS $^{+}$, a quasi-molecular ion peak appeared at $m / z, 642$ $[\mathrm{M}+\mathrm{H}]^{+}$; we could totally confirmed the double bond again. Lastly, under hydrogen reduction with Raney Ni catalysis, dehydroyunaconitine (2) converted to another product 3 (Fig. 1) which showed the same data $\left({ }^{1} \mathrm{H}\right.$ NMR, ${ }^{13} \mathrm{C}$ NMR, ESIMS) as standard sample of crassicauline A. In this way, semi synthesis of crassicauline A (3) from yunaconitine (1) had been completed.

We reported a new method to acquire crassicauline A (3), which had not been reported in the literature before. In our research, the semi synthesis of $\mathbf{3}$ from dehydroyunaconitine (2) was one of the most difficult steps. After a series of unsuccessful experiments, we finally found a practicable method. Compared with other methods, this one below was more suitable for production application and more concise; moreover, the cost was lower with higher yield.

In summary, we would continue to study the nature of yunaconitine (1) further. Previous studies have shown that (C-3, C-8, C-14) bonds of yunaconitine (1) have high pharmacological activity. Hence, we would tentatively synthesize a series of derivatives and establish some drug models in mice firstly; then, we expect to find better analgesic effect and fewer side effects with lower toxic compounds. Generally, this subject would be very useful for studies of structure-function relationship regard to diterpenoid alkaloids.

\section{Experimental Sections}

UV spectra were measured on a UV 210A Shimadzu spectrometer. IR spectra were recorded on a Vector 22 spectrometer with $\mathrm{KBr}$ pellets. Optical rotations were measured on Rudolph Autopol VI polarimeter. (Rudolph Research Analytical, Hacketstown, NJ, USA).One-dimensional NMR spectra were recorded with Avance spectrometer operating at $400 \mathrm{MHz}$ for ${ }^{1} \mathrm{H}$ and at $100 \mathrm{MHz}$ for ${ }^{13} \mathrm{C}$. The chemical shifts $(\delta)$ were measured in $\mathrm{CDCl}_{3}$ (solvent signals: $\delta_{\mathrm{H}}$ $\left.7.24, \delta_{\mathrm{C}} 76.90\right)$ with TMS as an internal standard. ESI mass spectra were recorded on VG Auto Spec-3000 spectrometer.

\subsection{Separation of Yunaconitine (1)}

In a normal method [11], firstly, we crushed the roots of A. hemsleyanum or A. geniculatum into powders. Secondly, above-mentioned powders $(1.5 \mathrm{~kg}$ ) were soaked by $10 \%$ sodium carbonate and extracted with chloroform. Thirdly, the concentrated extracts were diluted with water and acidified with $2 \%$ hydrochloric acid. Fourthly, the liquor from last step was filtered; the filter liquor was alkalized with ammonium hydroxide and extracted with ether. Lastly, the ether solvent was dried over anhydrous sodium sulfate and concentrated under vacuum to acquire yunaconitine (1) (15.6 g, yield: $1.04 \%$ ). After the final step, 1 was recrystallized several times by using ether to form crystals.

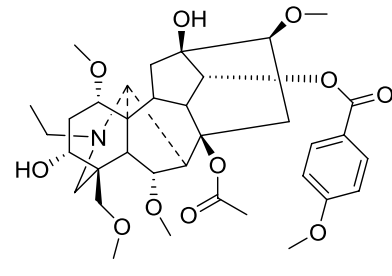

1

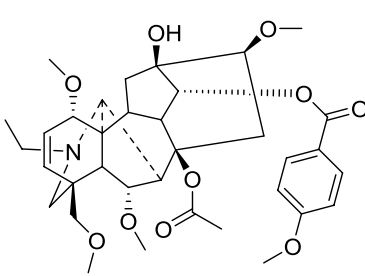

2

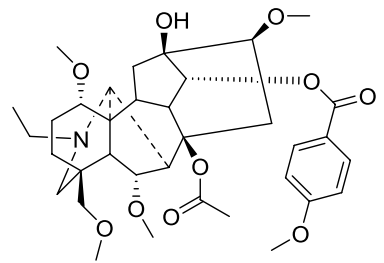

3

Fig. 1 Chemical transformation of $\mathbf{1}$ to $\mathbf{3}$ 


\subsection{Preparation of Dehydroyunaconitine (2)}

At first, yunaconitine (1) (1.07 g) was dissolved in thionyl chloride $(15 \mathrm{ml})$ and the resulting mixture in a round bottom flask was refluxed at $80{ }^{\circ} \mathrm{C}$ for $11 \mathrm{~h}$. In the second step, the mixture above was filtered and the filter liquor was evaporated to dryness under reduced pressure to give a residue (1.45 g). Thirdly, the residue was dissolved in $\mathrm{H}_{2} \mathrm{O}$ and alkalized to $\mathrm{pH} 8$ with saturated sodium carbonate. After that, the liquor from last step was extracted with dichloromethane and the dichloromethane solvent was dried over anhydrous sodium sulfate. Finally, the above-mentioned solvent was concentrated under vacuum to obtain dehydroyunaconitine (2) and the compound was purified with silica gel column chromatography (eluted with acetone: petroleum ether 3:7; chloroform: methanol 9.5:0.5, respectively) to afford the pure product 2. ( $836 \mathrm{mg}$, yield: $80.3 \%$ ). 2 could be recrystallized by using acetone: $\mathrm{n}$-hexane mixed in specific proportion to form crystals.

Dehydroyunaconitine (2): cubic crystals, $\mathrm{mp}$ 271.5-274.0 ${ }^{\circ} \mathrm{C} ;[\alpha]_{D}^{20.5}+42.65\left(c 0.068, \mathrm{CHCl}_{3}\right) ; \mathrm{UV}$ $(\mathrm{MeOH}) \lambda_{\max }(\log \varepsilon): 201.5$ (3.63), 207.5 (3.73), 259 (3.80) $\mathrm{nm}$. One of the IR $(\mathrm{KBr}) \nu_{\max } 1635 \mathrm{~cm}^{-1}$. The ${ }^{13} \mathrm{C}$ NMR spectra $\left(\mathrm{CDCl}_{3}, 100 \mathrm{MHz}\right)$ see Table 1 . ESIMS $\mathrm{m} / z, 642$ $[\mathrm{M}+\mathrm{H}]^{+}$; positive ion HRESIMS $\mathrm{m} / z 642.3200$ (calcd for $\left.\mathrm{C}_{35} \mathrm{H}_{47} \mathrm{NO}_{11}[\mathrm{M}+\mathrm{H}]^{+}, 642.3199\right)$.

\subsection{Preparation of Crassicauline A (3)}

Firstly, dehydroyunaconitine (2) (250 mg) was dissolved in $95 \%$ ethanol $(5 \mathrm{~mL})$ and under hydrogen reduction with Raney Ni catalysis $(1.5 \mathrm{~g})$, the resulting mixture in a round bottom flask was stirred at room temperature for $8 \mathrm{~h}$. Next, after reaction was completed, the Raney $\mathrm{Ni}$ was removed by filtration. Lastly, the filter liquor was evaporated to dryness under reduced pressure to acquire a product $\mathbf{3}$ as white powders (238 mg, yield: $94.9 \%$ ).

3 had the same data $\left({ }^{1} \mathrm{H}\right.$ NMR, ${ }^{13} \mathrm{C}$ NMR, ESIMS $)$ as standard sample of crassicauline $\mathrm{A}$; the ${ }^{13} \mathrm{C}$ NMR spectra of $\mathbf{3}$ see Table 1. At the same time, $\mathbf{3}$ also showed the same spot as crassicauline $\mathrm{A}$ in thin-layer chromatography. Therefore, the product 3 could be proved to be crassicauline A.

Acknowledgements The authors appreciate the members at Kunming Institute of Botany, Chinese Academy of Science for measuring the spectroscopic data and the members of Yunnan toxic medicinal plants research team for picking and treatment of pharmaceutical raw materials. This work was supported by "YunLing Scholars" project (2020HC008).

\section{Compliance with Ethical Standards}

Conflict of interest: The authors declare no conflict of interest.
Table $1{ }^{13} \mathrm{C}$ NMR Data of compounds $\mathbf{1 , 2}, \mathbf{3}$ in $\mathrm{CDCl}_{3}$

\begin{tabular}{|c|c|c|c|}
\hline NO & 1 & 2 & 3 \\
\hline $\mathrm{C}(1)$ & 83.1 & 83.5 & 85.0 \\
\hline $\mathrm{C}(2)$ & 33.5 & 125.3 & 26.3 \\
\hline $\mathrm{C}(3)$ & 71.4 & 137.6 & 34.9 \\
\hline $\mathrm{C}(4)$ & 43.1 & 40.8 & 39.1 \\
\hline$C(5)$ & 47.4 & 47.8 & 50.2 \\
\hline$C(6)$ & 82.2 & 80.9 & 83.8 \\
\hline$C(7)$ & 44.7 & 44.5 & 45.1 \\
\hline $\mathrm{C}(8)$ & 85.6 & 85.8 & 85.6 \\
\hline $\mathrm{C}(9)$ & 48.7 & 46.4 & 50.0 \\
\hline$C(10)$ & 40.8 & 41.0 & 41.0 \\
\hline $\mathrm{C}(11)$ & 50.2 & 48.8 & 49.1 \\
\hline $\mathrm{C}(12)$ & 35.1 & 33.8 & 35.8 \\
\hline $\mathrm{C}(13)$ & 74.6 & 74.8 & 74.8 \\
\hline $\mathrm{C}(14)$ & 78.5 & 78.5 & 78.6 \\
\hline$C(15)$ & 39.5 & 40.1 & 39.3 \\
\hline$C(16)$ & 83.5 & 83.5 & 83.1 \\
\hline $\mathrm{C}(17)$ & 61.6 & 59.2 & 61.7 \\
\hline $\mathrm{C}(18)$ & 76.7 & 78.2 & 80.4 \\
\hline C(19) & 48.7 & 52.6 & 53.6 \\
\hline $\mathrm{N}-\mathrm{CH}_{2}-\mathrm{CH}_{3}$ & 47.4 & 47.8 & 49.6 \\
\hline $\mathrm{N}-\mathrm{CH}_{2}-\mathrm{CH}_{3}$ & 13.1 & 12.4 & 13.4 \\
\hline $1-\mathrm{OCH}_{3}$ & 55.7 & 56.1 & 56.0 \\
\hline 6- $\mathrm{OCH}_{3}$ & 58.7 & 58.8 & 58.7 \\
\hline $16-\mathrm{OCH}_{3}$ & 57.7 & 57.8 & 57.7 \\
\hline $18-\mathrm{OCH}_{3}$ & 59.0 & 59.2 & 59.0 \\
\hline $\mathrm{O}=\underline{\mathrm{C}}-\mathrm{CH}_{3}$ & 169.9 & 169.8 & 169.7 \\
\hline $\mathrm{O}=\mathrm{C}-\underline{\mathrm{CH}}_{3}$ & 21.5 & 21.5 & 21.6 \\
\hline$C\left(7^{\prime \prime}\right)$ & 166.1 & 165.8 & 166.0 \\
\hline $\mathrm{C}\left(1^{\prime \prime}\right)$ & 122.5 & 122.6 & 122.8 \\
\hline $\mathrm{C}\left(2^{\prime \prime}\right)$ or $\mathrm{C}\left(6^{\prime \prime}\right)$ & 131.6 & 131.6 & 131.7 \\
\hline $\mathrm{C}\left(3^{\prime \prime}\right)$ or $\mathrm{C}\left(5^{\prime \prime}\right)$ & 113.7 & 113.8 & 113.7 \\
\hline $\mathrm{C}\left(4^{\prime \prime}\right)$ & 163.5 & 163.5 & 163.5 \\
\hline 4"-Oㅡㅐ ${ }_{3}$ & 55.3 & 55.4 & 55.4 \\
\hline
\end{tabular}

Chemical shifts $(\delta)$ in ppm relative to TMS in $\mathrm{CDCl}_{3}$

Ethical approval All applicable international, national, and/or institutional guidelines for the care and use of animals were followed.

Informed consent Informed consent was obtained from all individual participants included in the study.

Open Access This article is licensed under a Creative Commons Attribution 4.0 International License, which permits use, sharing, adaptation, distribution and reproduction in any medium or format, as long as you give appropriate credit to the original author(s) and the source, provide a link to the Creative Commons licence, and indicate if changes were made. The images or other third party material in this article are included in the article's Creative Commons licence, unless indicated otherwise in a credit line to the material. If material is not included in the article's Creative Commons licence and your intended use is not permitted by statutory regulation or exceeds the permitted use, you will 
need to obtain permission directly from the copyright holder. To view a copy of this licence, visit http://creativecommons.org/licenses/by/4.0/.

\section{References}

1. S.Y. Chen, Acta Chem. Sin. 37, 15-20 (1979)

2. C. Wu, J. Xinjiang Med. Univ. 34, 1153-1157 (2011)

3. H.B. Zhang, W.Y. Hu, L. Li, X.T. Dai, D.Z. Zhang, China. Patent 1054976, 2 (1991)

4. R.P. Zhang, S.Y. Chen, J. Zhou, Acta Bot. Yunnanica Plant Divers. 20, 474-478 (1998)
5. X.C. Tang, X.J. Liu, W.H. Lu, Acta Pharm. Sin. 21, 886 (1986)

6. Y.Q. Liu, X.N. Ding, Y.D. Zhang, Chin. J. Pain Med. 17, 314-315 (2011)

7. X.H. Zhen, Clin. Med. 25, 161 (2005)

8. A. Chodoeva, J.-J. Bosc, J. Robert, Aconitum Alkaloids and Biological Activities. Natural Products, vol. 48 (Springer, Heidelberg, 2013), pp. 1503-1523

9. X.C. Tang, Chin. J. N. Drugs Clin. Remedies. 5, 120-121 (1986)

10. The Pharmaceutical Standard, the Healthy Department of Yunnan Province, 1985

11. R.E. Gilman, L. Marion, Can. J. Chem. 40, 1713-1716 (1962) 